\title{
Outcome of Tibial Fractures Cleaned and Irrigated with Tetrachlorodecaoxygen Solution and Primary Plate Fixation
}

\author{
D Ismono, MD, H Herman, MD \\ Department of Orthopaedic Surgery and Traumatology, School of Medicine Padjadjaran State University-Hasan \\ Sadikin General Hospital, Bandung, Indonesia
}

\begin{abstract}
In this study we seek to evaluate the value of tetrachlorodecaoxygen as an intra and postoperative adjuvant in the surgical management of primarily closed tibial fractures fixed with plate and screws. We reasoned that its prophagocytic and antiinflammation properties should decrease acute inflammation and associated complications. Of 41 cases of tibial fractures included in the study, seven were grade III open fractures. No adverse effects were observed from the use of tetrachlorodecaoxygen. There was no occurrence of acute compartment syndromes or chronic deep tissue infections. All subjects were able to bear weight within 16 to 24 weeks. We concluded that the use of tetrachlorodecaoxygen is of benefit when used as an adjuvant in the primary fixation and wound closure of tibial fractures.
\end{abstract}

Key Words:

Tibial fracture, Implant-associated infection, Tetrachlorodecaoxygen, Oxoferin $\AA$

\section{INTRODUCTION}

About a fourth of tibial fractures are open cases, in which fractured bones are exposed through an open wound ${ }^{1,2}$. Gustillo proposed a categorization based on the degree of injury to the soft tissue; open fractures with wound sizing less than $1 \mathrm{~cm}$ are classified as grade I, open fractures with wound sizing less than $10 \mathrm{~cm}$ are classified as grade II, open fractures with wound sizing more than $10 \mathrm{~cm}$ are classified as grade III $^{3}$. Grade III fractures are further graded based on the ability to cover the defect (IIIA, defect amenable to closure; IIIB, defect not amenable to closure; and, IIIC presence of neurovascular injury) ${ }^{4}$.

One management option for tibial fractures is primary plate and screw fixation, but it has been associated with acute and/or chronic inflammation attributed to the extensive softtissue damage resulting from the surgical procedure, in addition to the initial damage caused by the trauma ${ }^{5-8}$. Tetrachlorodecaoxygen may help to decrease inflammation and associated complications stemming from plate and screw fixation. It is an agent that is currently used to attenuate inflammation in transplantation patients, and patients with chronic inflammation due to immunosuppression. This agent is capable of promoting local immunity while at the same time restricting inflammation by augmenting phagocytic activity of macrophages and suppressing macrophage ability to recruit other inflammatory cells by interfering with its antigen presenting activity ${ }^{9,10}$. A prototype of tetrachlorodecaoxygen, WF10, has been shown to be safe and has had promising results when used as an adjuvant in a systemic therapy against transplant rejection and chronic infection associated with immunocompromised patients ${ }^{11-14}$. In the present study, we evaluated the use of tetrachlorodecaoxygen, for cleaning and irrigating tibial fractures managed with primary plate fixation, including open fracture cases where wounds are primarily closed.

\section{MATERIALS AND METHODS}

Forty-one tibial fracture cases during the period of 20002004 , were prospectively managed with primary plate and screw fixation. Of these, 27 were closed and 14 were open fractures. Of the open fractures, three were type I, four were type II, six were type IIIA and one was type IIIB, according to the Gustilo-Anderson classification.

Tetrachlorodecaoxygen (Oxoferin ${ }^{\circledR}, 0.002 \%$ in $30 \mathrm{ml}$, manufactured by Pharos, Indonesia) was used for all patients in this study. For closed fractures and open grade I and II fractures, tetrachlorodecaoxygen solution was used intraoperatively to soak the plate, screws and wound prior to implant insertion and immediately prior to wound closure (Figure 1). For open grade IIIA and B fractures, the solution was also used as a once a day 2.5-5 cc wound irrigatant through a Penrose drain for three to five days post surgery (Figure 2). For fixation, we used 8 hole, $4.5 \mathrm{~mm}$ narrow plates (Figure 1), approximately $13.5 \mathrm{~mm}$ in length, $12.0 \mathrm{~mm}$ wide, and $3.6 \mathrm{~mm}$ thick (manufactured by Martin, Germany).

Following surgery, wounds were monitored for signs of inflammation and compartment syndrome. Signs of superficial and deep wound infections were monitored 


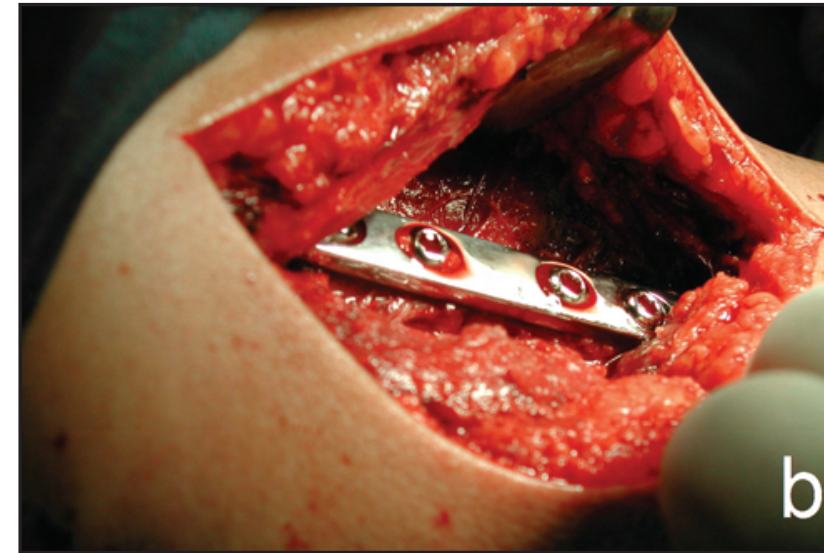

Fig. 1: Internal fixation with plate and screws and irrigation (soaking) with tetrachlorodecaoxygen solution immediately prior to wound closure.

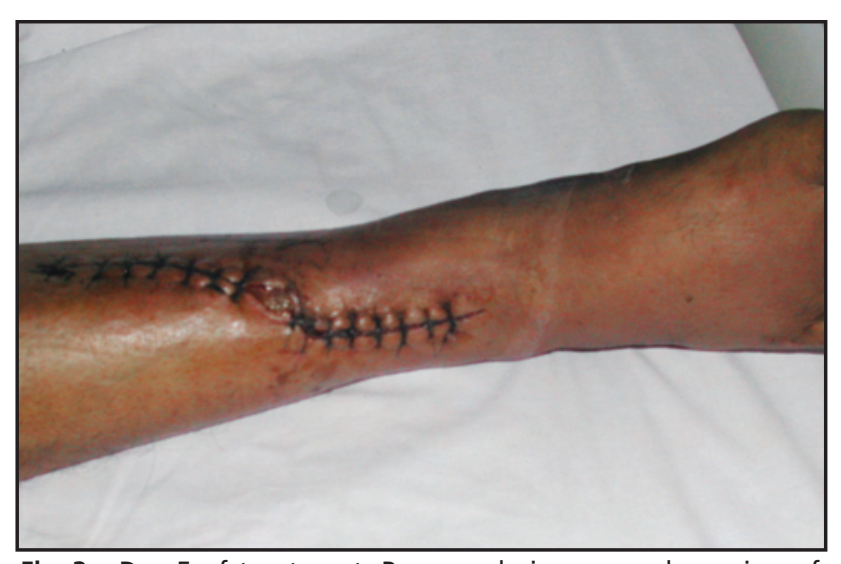

Fig. 3: Day 5 of treatment, Penrose drain removed, no sign of extensive inflammation or skin infection.

during follow up at two, four and eight weeks, and once every three months thereafter (Figure 3).

Ethical approval for this study was granted by the Ethical committee of Hasan Sadikin General Hospital and Boromeus Hospital, and in accordance with Helsinki treaty of 1975.

\section{RESULTS}

Forty-one subjects consisting of 28 males (average age 34.7 years; range, 14.7 to 67.4 years) and 13 females (average age 34.5 years; range 13.2 to 64.8 years) were included in the study. The mean number of days of inpatient treatment prior to discharge was five days. Thirty-four cases consisting of 27 closed fractures and 7 type I/II open fractures treated with intraoperative tetrachlorodecaoxygen solution. Seven cases of type III open fractures were treated with intra and postoperative tetrachlorodecaoxygen solution. Wounds were all primarily closed.

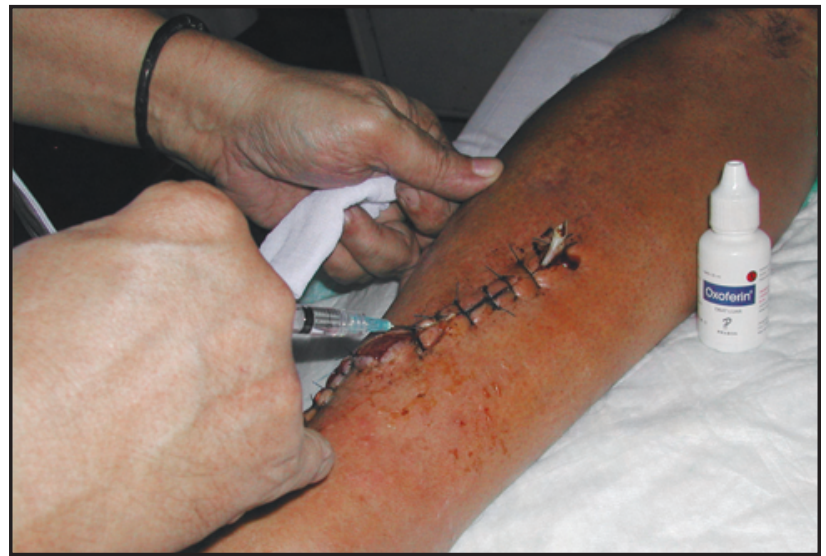

Fig. 2: First day of treatment at day1 post surgery; wound was irrigated with pulsatile injection of tetrachlorodecaoxygen from proximal end and drained through a Penrose drain at the opposite end.

We observed neither extensive inflammation nor sign of impending compartment syndrome in any of the study subjects. There were also no cases of either superficial or deep wound infection. All cases were partially or fully weight bearing within 16 to 24 weeks postoperatively with a median of 20 weeks. Radiographically, all cases showed complete bony union at 16-28 weeks after surgery, with a median of 20 weeks. No significant loosening or septic pseudoarthrosis was observed in any of the cases.

\section{DISCUSSION}

The choice of management for tibial fractures depends on the types and degree of the fracture, but also on surgeon preference. Internal fixation with plate and screws for tibial fracture has fallen out of preference due to the high degree of tissue damage and associated infection resulting from the surgical procedure. Due to its relatively low cost, however, plate and screw fixation is still widely used for tibial fracture in this country.

Traditionally, wounds associated with open fractures, especially with grade III fractures are not closed after initial wound debridement. Recent studies have shown the advantages of primarily closing such wounds, and reported a comparable complication rate to delayed closure ${ }^{15,16}$. Intraoperative use of tetrachlorodecaoxygen solution for the treatment of closed and type I/II open fractures with primary closure of wounds did not result in a higher rate of complications. Twenty-seven closed cases and seven open cases healed with average time of 20 weeks. There was no occurrence of compartment syndrome or implant associated infections in all cases, which compares favourably to our personal experience and published results with other methods. We hypothesized that the use of tetrachlorodecaoxygen solution may decrease inflammation resulting from damages to the tissue resulting from implant insertion procedure. 
Similarly, none of the primary closed grade III open fractures developed compartment syndromes, implant associated infection, or other complications. We did not observe loosening of implants or screws during follow up and all subjects were partially or fully weight bearing with a median of 24 weeks. For open grade III fractures, tetrachlorodecaoxygen solution may also help tissue to cope with the tension resulting from closure of the wounds.

The observational nature of our current study may not offer the best evidence for clinical practice. The majority of cases reported here were fractures of the tibial diaphysis. Further evaluation for metaphyseal or intra articular fractures may be necessary.

\section{CONCLUSION}

The use of tetrachlorodecaoxygen solution as an adjuvant to primary plate fixation and wound closure of a tibial fracture may be beneficial due to its anti-inflammatory and effect. The solution can be used for closed and selected open tibial fractures treated with primary plate fixation.

\section{ACKNOWLEDGMENT}

We thank the Dean of the School of Medicine at Padjadjaran State University, the Director of Hasan Sadikin General Hospital, and the Director of Borromeus Hospital for their support and encouragement.

Conflict of interest statement

The authors declare no conflict of interest. The authors did not receive financial compensation for the use of tetrachlorodecaoxygen solution in this study. 


\section{REFERENCES}

1. McGrath L, Royston. Fractures of the tibial shaft. Surgery 2003; 21(9): 231-5.

2. Court-Brown CM, McBirnie J. The epidemiology of tibial fractures. J Bone Joint Surg 1995; 77-B(3): 417-21.

3. Gustilo RB, Anderson JT. Prevention of infection in the treatment of one thousand and twenty-five open fractures of long bones: retrospective and prospective analyses. J Bone Joint Surg 1976; 58-A(4): 453-8.

4. Gustilo RB, Gruninger RP, Davis T. Classification of type III (severe) open fractures relative to treatment and results. Orthopedics 1987; 10(12): 1781-8.

5. Bach AW, Hansen ST Jr. Plates versus external fixation in severe open tibial shaft fractures. A randomized trial. Clin Orthop Relat Res 1989; 241: 89-94.

6. Bhandari M, Guyatt GH, Swiontkowski MF, Schemitsch EH. Treatment of open fractures of the shaft of the tibia. J Bone Joint Surg 2001; 83-B(1): 62-8

7. Clifford RP, Beauchamp CG, Kellam JF, Webb JK, Tile M. Plate fixation of open fractures of the tibia. J Bone Joint Surg 1988; 70-B(4): 644-8.

8. Behrens F, Searls K. External fixation of the tibia. Basic concepts and prospective evaluation. J Bone Joint Surg 1986; 68-B(2): 246-54.

9. McGrath MS, Benike C, Kuehne FW, Engleman E. Effect of WF10 (TCDO) on antigen presentation. Transplant Proc 1998; 30(8): 4200-4.

10. Giese T, McGrath MS, Stumm S, Schempp H, Elstner E,. Meuer SC. Differential effects on innate versus adaptive immune responses by WF10. Cell Immunol 2004; 229(2): 149-58.

11. Raffanti SP, Schaffner W, Federspiel CF, Blackwell RB, Ching OA, Kuhne FW. Randomized, double-blind, placebo-controlled trial of the immune modulator WF10 in patients with advanced AIDS. Infection 1998; 26(4): 202-7.

12. Kemp E, Dieperink H, Horn T,Johansen A, Jensen J, Kemp G, et al., WF10 in xenotransplantation-a potential new approach. Transplant Proc 2000; 32(5): 1018-9.

13. Kemp E, Dieperink H, Hansen T, Horn T, Johansen A, Jensen J et al. Immunosuppression in xenotransplantation with Wf10. Pharmacol Toxicol 2002; 90(6): 346-8.

14. Veerasarn V, Khorprasert C, Lorvidhaya V, Sangruchi S, Tantivatana T, Narkwong L, et al. Reduced recurrence of late hemorrhagic radiation cystitis by WF10 therapy in cervical cancer patients: a multicenter, randomized, two-arm, open-label trial. Radiother Oncol 2004; 73(2): 179-85.

15. DeLong WG Jr, Born CT, Wei SY, Petrik ME, Ponzio R, Schwab CW. Aggressive treatment of 119 open fracture wounds. $J$ Trauma 1999; 46(6): p. 1049-54.

16. Stalekar H, Fuckar Z, Ekl D, Sustic A, Loncarek K, Ledic D. Primary vs secondary wound reconstruction in Gustilo type III open tibial shaft fractures: follow-up study of 35 cases. Croat Med J 2003; 44(6): 746-55. 